\title{
Uma Análise da Constituição de Saberes Relativos ao Ensino de Física Quântica em um Curso de Licenciatura
}

\author{
An Analysis of the Constitution of Knowledge Related to the \\ Teaching of Quantum Physics in an Undergraduate Course
}

\author{
Marcelo Zanotello' \\ Leiana Camargo ${ }^{1}$
}

Universidade Federal do ABC (UFABC), Centro de Ciências Naturais e Humanas, Santo André, SP, Brasil.
Autor correspondente: marcelo.zanotello@ufabc.edu.br

Resumo: Professores são profissionais em contínuo desenvolvimento, constituindo ao longo de sua trajetória pessoal e formativa determinados saberes que são mobilizados em sua prática. Nosso objetivo consiste em analisar indícios da constituição de saberes relativos ao ensino de física quântica por estudantes de um curso de licenciatura em física. A inserção da física quântica na educação básica tem sido objeto de estudos que indicam a pertinência de investigações sobre a formação inicial de professores de física, considerando que esta deve propiciar oportunidades para que os envolvidos expressem suas concepções, dificuldades conceituais e discutam sobre estratégias e recursos didáticos. Com base na caracterização de Tardif para os saberes docentes, realizamos uma análise discursiva de entrevistas em profundidade com dois estudantes utilizando pressupostos da análise do discurso francesa. Propomos uma categorização de aspectos relativos a esses saberes, evidenciando suas constituições com posicionamentos críticos dos estudantes sobre conceitos da física quântica e seu ensino.

Palavras-chave: Ensino de física; Física quântica; Análise do discurso; Formação inicial de professores.

\begin{abstract}
Theachers are professionals in continuous development, constituting throughout their personal and formative trajectory knowledges that are mobilized in their practices. Our objective is to analyze evidences of the constitution of certain knowledges related to the teaching of quantum physics by undergraduate students. The inclusion of quantum physics in basic education has been object of studies that indicate the need to promote investigations about the initial training of physics' teachers, considering that this formation should provide opportunities for the students express their conceptions, conceptual difficulties and discuss strategies and didactic resources. Based on Tardif's characterization of teaching knowledge, we conducted a discursive analysis of in-depth interviews with two students, using concepts of the French Discourse Analysis. We propose a categorization of aspects related to the constitution of those knowledges and we noted critical positions about concepts of the quantum physics and its teaching.
\end{abstract}

Keywords: Physics teaching; Quantum physics; Discourse analysis; Teacher's initial training.

Recebido em: 16/05/2019

Aprovado em: 15/08/2019 


\section{Introdução}

Estudos no campo educacional reconhecem o professor como um profissional em contínuo desenvolvimento, constituindo determinados saberes - competências, habilidades, conhecimentos e atitudes - que são mobilizados em sua prática e necessários para a consecução dos processos de ensino e aprendizagem (LIBÂNEO, 2004; SHULMAN, 1986; TARDIF; LESSARD, 2011).

Tardif (2014) caracteriza os saberes profissionais dos professores como temporais, plurais e heterogêneos, personalizados, situados e humanizados, propondo uma classificação em quatro grandes conjuntos em função de suas naturezas: os saberes da formação profissional (das ciências da educação e da ideologia pedagógica), os saberes disciplinares, os curriculares e os experienciais. Apesar da análise de Tardif (2014) fundamentar-se principalmente no exercício profissional da docência, o autor destaca que a constituição desses saberes origina-se antes mesmo da formação inicial nos cursos superiores de licenciatura. Para Tardif (2000), antes de exercerem suas funções profissionais, os professores dedicaram tempo considerável de suas vidas em seu futuro espaço de trabalho: a escola. Boa parte do que sabem sobre o ensino provém da análise, mesmo que indireta, dos professores com os quais conviveram no que diz respeito a suas práticas de ensino, seus papeis como professores, seus planejamentos, como se organizaram em relação ao tempo de aula, etc. Ou seja, os saberes dos professores originam-se das imagens que constituem sobre o que é e como trabalha um professor (TARDIF, 2000).

Por uma perspectiva discursiva baseada na Análise de Discurso (AD) de vertente francesa (MAINGUENEAU, 2015; ORLANDI, 2010), podemos considerar que esse aspecto da constituição dos saberes (e provavelmente não apenas esse) é a manifestação de um efeito ideológico. Ele está relacionado à formação ideológica na qual se insere o futuro professor; ao imaginário social que compartilha e aos sentidos que atribui à docência a partir de suas experiências de vida, no processo de interpelação do indivíduo em sujeito pela ideologia conforma preconiza a AD.

No presente trabalho nosso objetivo é analisar aspectos do processo de constituição de determinados saberes associados à docência por estudantes de um curso de licenciatura em física. Especificamente, no que se refere às possibilidades e limitações para o ensino de física quântica na Educação Básica, quais saberes os estudantes sujeitos de nossa investigação mobilizam e constituem acerca dessa temática? Esta questão sintetiza nosso problema central de pesquisa. Com base em uma análise discursiva dos dizeres dos estudantes, realizada a partir de entrevistas semiestruturadas, buscamos indícios da constituição dos saberes disciplinares, curriculares e daqueles relacionados à formação profissional, de acordo com a classificação de Tardif (2014).

O estudo se deu no contexto de uma disciplina sobre princípios de mecânica quântica e a análise nos permitiu não apenas identificar indícios da constituição de certos saberes, mas também propormos uma categorização dos mesmos. Entendemos que essa proposta de categorização se configura como uma contribuição do presente trabalho, que pode auxiliar futuras análises acerca das constituições dos saberes para a docência na formação inicial de professores de física em pesquisas que compartilhem os referenciais teóricos e metodológicos que adotamos. 
Na próxima seção apresentamos uma síntese da fundamentação teórica em que nos baseamos para, em seguida, destacarmos os aspectos metodológicos da investigação. $\mathrm{Na}$ seção de análise apresentamos uma proposta de categorização para os saberes com base nos discursos dos estudantes e, por fim, realizamos nossas considerações finais.

\section{Fundamentação Teórica}

Os saberes da formação profissional, oriundos das ciências da educação e da ideologia pedagógica, são compreendidos como um conjunto de saberes que se estabelecem nos momentos de formação inicial e continuada; um conjunto de conhecimentos pedagógicos que são constituídos por técnicas e métodos das ciências humanas e da educação. Tais conhecimentos se tornam saberes relacionados à formação científica dos professores e podem se transformar em prática científica. A ideologia pedagógica pode ser entendida como um saber pedagógico formado pela interação entre conhecimentos teóricos e práticos relacionados à profissão docente. De acordo com Tardif (2014, p. 37),

[...] os saberes pedagógicos apresentam-se com doutrinas ou concepções provenientes de reflexões sobre a prática educativa no sentido amplo do termo, reflexões racionais e normativas que conduzem a sistemas mais ou menos coerentes de representação e de orientação da atividade educativa [...].

Por sua vez, os saberes disciplinares são relacionados às diversas áreas do conhecimento. Esses saberes constituem-se principalmente durante os processos de formação inicial e continuada, compondo a prática docente. Eles são selecionados e administrados pelas comunidades científicas e pelas instituições educacionais que possibilitam seu acesso por parte dos professores, a partir de uma tradição cultural resguardada em entidades sociais produtoras e gestoras desses saberes. O domínio dos conteúdos disciplinares compreende os fenômenos, conceitos, leis e processos de uma determinada ciência, bem como procedimentos para sua mobilização, representação e validação para cada área de conhecimento. Tardif (2014, p. 38) esclarece que:

[...] a prática docente incorpora ainda saberes sociais definidos e selecionados pela instituição universitária. Estes saberes integram-se igualmente à prática docente através da formação (inicial e contínua) dos professores nas diversas disciplinas oferecidas pela universidade. Podemos chamá-los de saberes disciplinares. São saberes que correspondem aos diversos campos do conhecimento, aos saberes de que dispõe a nossa sociedade, tais como se encontram hoje integrados nas universidades, sob a forma de disciplinas, no interior de faculdades e de cursos distintos.

Os saberes curriculares são conhecimentos relacionados aos elementos que constituem os currículos oficiais, como os "[...] discursos, objetivos, conteúdos e métodos a partir dos quais a instituição escolar categoriza e apresenta os saberes sociais por ela definidos e selecionados como modelos da cultura erudita e de formação para a cultura erudita" (TARDIF, 2014, p. 38). Esses saberes estão relacionados à forma como as instituições educacionais fazem a gestão dos conhecimentos socialmente produzidos e que devem ser aprendidos pelos estudantes, considerando o contexto de cada escola com suas especificidades. Durante a formação inicial, os professores têm certo contato com os saberes curriculares e, assim que chegam às instituições de ensino, são incumbidos de realizá-los. 
Ao propormos uma investigação do processo de constituição desses saberes realizando uma análise discursiva dos dizeres de determinados estudantes cabe explicitarmos, ainda que brevemente, a concepção sobre a linguagem e seu funcionamento em que nos baseamos para evidenciar a produção se sentidos por parte desses estudantes. Tal concepção baseiase em pressupostos da Análise de Discurso (AD) em sua vertente francesa. De acordo com Orlandi (2010, p. 26-27), "[...] a AD visa à compreensão de como um objeto simbólico produz sentidos, como ele está investido de significância para e por sujeitos". A escolha desse referencial teórico se dá em virtude da importância que o mesmo confere às chamadas condições de produção imediatas dos discursos e às formações imaginárias e discursivas nas quais os sujeitos estão inseridos. Além de suporte do pensamento e meio de transmissão de informação, a linguagem é considerada produto do trabalho das pessoas num processo de interação histórico-social, que se constrói na relação com o mundo. Nessa perspectiva, a linguagem não é transparente, não existindo um sentido único a ser decodificado em um enunciado. $O$ discurso é entendido como efeito de sentidos entre locutores e a AD procura uma compreensão para a formulação e circulação dos discursos.

Diante de um objeto simbólico qualquer, o ser humano é instado à interpretação. As possibilidades de atribuição de sentidos no ato interpretativo são condicionadas pelo contexto histórico-social e pela ideologia, entendida como o imaginário que permeia as relações do sujeito com suas condições de existência, permitindo o estabelecimento de relações entre pensamento, linguagem e mundo. Nesta perspectiva, a interpretação se dá mediante condições de produção envolvendo os contextos histórico e social de formulação dos discursos, os interlocutores, as posições em que os interlocutores se situam e em que são vistos, as imagens que fazem de si e dos outros, bem como do objeto da fala (ALMEIDA, 2004). As condições de produção imediatas referem-se aos contextos locais de produção dos enunciados, compreendendo fundamentalmente os sujeitos e a situação em que estão inseridos. Nesta pesquisa, os sujeitos falam sobre o ensino da física quântica tanto como futuros professores de física, como estudantes em uma disciplina de um curso de graduação. A determinação histórica do sentido fundamenta-se no conceito de memória que, ao ser tratada como interdiscurso, denomina-se memória discursiva. O interdiscurso

[...] é definido como aquilo que fala antes, em outro lugar, independentemente. Ou seja, é o que chamamos de memória discursiva: o saber discursivo que torna possível todo o dizer e que retorna sob a forma do pré-construído, o já dito, que está na base do dizível, sustentando cada tomada da palavra. O interdiscurso disponibiliza dizeres que afetam o modo como o sujeito significa em uma situação discursiva dada (ORLANDI, 2010, p. 31).

A análise no processo de interpretação torna possível a compreensão do discurso a partir de suas condições de produção, estabelecendo relações com a memória e remetendo a uma formação discursiva (ORLANDI, 2010, p. 42). Segundo a autora, "[...] a formação discursiva se define como aquilo que em uma formação ideológica dada - ou seja, a partir de uma posição dada em uma dada conjuntura social e histórica - determina o que pode e deve ser dito" (ORLANDI, 2010, p. 43). 


\section{Aspectos Metodológicos}

Nesta pesquisa empírica e qualitativa (BOGDAN; BIKLEN, 1994), a coleta de dados se deu por entrevistas semiestruturadas. A entrevista semiestruturada "[...] parte de certos questionamentos básicos, apoiados em teorias e hipóteses que interessam à pesquisa e que, em seguida, oferece amplo campo de interrogativas, fruto de novas hipóteses que vão surgindo à medida que se recebem as respostas do informante". (TRIVIÑOS, 1987, p. 146). Desse modo, o roteiro flexível de uma entrevista semiestruturada permite ao pesquisador adaptá-lo com o intuito de obter o máximo de informações possíveis e confere ao entrevistado um grau de liberdade maior para expor suas opiniões, dificuldades e evidenciar o que é mais relevante para ele.

As entrevistas semiestruturadas foram realizadas com dois estudantes do curso de licenciatura em física, no final da disciplina 'Princípios de mecânica quântica' no primeiro período letivo de 2017. As entrevistas foram integralmente registradas em gravações audiovisuais. Abaixo, apresentamos o roteiro da entrevista, elaborado a partir dos sentidos que desejávamos investigar enquanto os estudantes refletiam sobre a importância de se ensinar física quântica, as dificuldades supostamente envolvidas nesse ensino, quais tópicos seriam selecionados e como poderiam ser ensinados.

\section{Roteiro da Entrevista Semiestruturada}

- O que mais te chama atenção na mecânica quântica, ou o que você acha mais interessante?

- Em sua opinião, qual seria a importância de se aprender física quântica no ensino médio?

- Você acha que é possível ensinar tópicos de física quântica no ensino médio? Justifique

- Você abordaria algum tema de física quântica em sala de aula?

- Para você, os conteúdos de física quântica trazem algumas contribuições para os alunos? Quais?

- Em que aspectos a abordagem de tópicos da física quântica no ensino médio contribuem para a formação do estudante?

- Você se encontra preparado para ensinar física quântica para seus alunos? Por quê?

- Você acha que os alunos do ensino médio se interessariam por esse conteúdo?

- Que dificuldades você prevê existirem ao serem trabalhados conteúdos de física quântica no ensino médio?

- Como esses conteúdos poderiam ser abordados?

- Que recursos didáticos e estratégias você utilizaria para introduzir temas de física quântica em aulas na Educação Básica?

- O que você acha da inclusão do formalismo matemático? É necessário aprender o conceito para depois realizar as contas?

- As disciplinas sobre física quântica que você estudou durante a graduação o prepararam para discutir o tema com alunos do ensino médio?

Para preservação da identidade dos sujeitos da pesquisa, são estabelecidos os nomes fictícios Rafa e Caio para menciona-los. Esses estudantes foram escolhidos por aceitarem colaborar com a pesquisa, terem disponibilidade de tempo para as entrevistas e por que tinham uma participação assídua durante a disciplina. Ao todo, a turma continha cinco estudantes. 
A abordagem da docente responsável pela disciplina priorizou aspectos qualitativos, conceituais, filosóficos e culturais, não enfatizando apenas o formalismo matemático. $\mathrm{O}$ intuito foi possibilitar aos estudantes a compreensão de que a ciência é uma construção humana, de modo que sua inserção na educação básica possa ser pensada a partir das perspectivas conceitual, ontológica e epistemológica.

A docente organizou-a em cinco temas: radiação de corpo negro e quantização da energia; experimentos, comportamentos e interpretações em sistemas quânticos; fundamentos do formalismo matemático da mecânica quântica; interpretações filosóficas da mecânica quântica; ensino de física quântica. Pela perspectiva discursiva que adotamos, a disciplina tal como desenvolvida funciona como uma condição de produção imediata de sentidos para os estudantes, contribuindo na constituição de suas memórias discursivas acerca dos objetos de investigação aos quais nos dedicamos.

Do ponto de vista metodológico, a AD estabelece duas passagens fundamentais para o trabalho com o material empírico (ORLANDI, 2010). A primeira incide sobre a superfície linguística, entendida como o material de linguagem bruto coletado. A construção do corpus e a análise estão ligadas: decidir o que faz parte do corpus em função dos objetivos da investigação já é, em parte, decidir acerca das propriedades discursivas que se procura evidenciar. Essa passagem inicial, que visa gerar um objeto discursivo a partir da superfície linguística, denomina-se de-superficialização e consiste na análise da materialidade linguística: o que se diz, como se diz, quem diz, em que circunstâncias diz, etc. Nela, analisase o que é dito em um discurso específico e o que é dito em outros, produzidos em outras condições e afetados por diferentes memórias discursivas. A segunda passagem diz respeito à transformação do objeto discursivo em processo discursivo. Nessa etapa, procura-se relacionar as formações discursivas manifestas com a formação ideológica que as rege. Trabalhamos com o material empírico a partir dessa perspectiva metodológica orientada pela AD.

\section{Análise}

A fim de apresentarmos e analisarmos nossos resultados, optamos por subdividir esta seção em três partes. Na primeira parte apresentamos a categorização proposta para os saberes. Na segunda exemplificamos as bases empíricas para a categorização, trazendo trechos das falas dos estudantes nas quais evidenciamos as ocorrências das categorias. Tratase da etapa de elaboração do objeto discursivo (de-superficialização) a que a AD se refere. Por fim, na terceira parte, destacamos alguns sentidos mobilizados pelos entrevistados relacionando-os a formações discursivas e ideológicas que constituem o imaginário dos sujeitos envolvidos em relação aos temas abordados.

\section{Uma Categorização para os Saberes}

A partir da perspectiva de Tardif (2014) sobre os saberes docentes, evidenciamos nos discursos dos estudantes ao todo vinte categorias que compõem três dos saberes da formação profissional. Cabe ressaltar que a proposição de tais categorias é fruto de um gesto interpretativo dos autores desta pesquisa acerca da teoria dos saberes docentes, posta em relação com os discursos dos estudantes no contexto da disciplina em questão. 
As categorias abarcam os seguintes saberes: cinco categorias referem-se aos saberes disciplinares (SD), sete aos saberes da formação profissional (os saberes pedagógicos, SP) e oito aos saberes curriculares (SC). Os quadros 1, 2 e 3 apresentam a definição de cada categoria, que está codificada e associada a um saber específico. Por exemplo, a categoria SD01 refere-se a 'conteúdo importante' e ao grupo do saber disciplinar'SD', onde '01'é apenas uma numeração para auxiliar nas associações entre os trechos das falas dos estudantes com os saberes e categorias mobilizados.

Quadro 1 - Categorias associadas aos saberes disciplinares

\begin{tabular}{|l|l|l|}
\hline \multicolumn{2}{|c|}{ Saberes Disciplinares (SD) } \\
\hline Código & \multicolumn{1}{|c|}{ Categorias } & \multicolumn{1}{c|}{ Definição } \\
\hline SD01 & Conteúdo importante & $\begin{array}{l}\text { O licenciando menciona conteúdos da física quântica que considera impor- } \\
\text { tantes para o aluno na educação básica aprender. }\end{array}$ \\
\hline SD02 & Conteúdo aplicado & $\begin{array}{l}\text { Atribui sentidos para temas da física quântica que permitiriam aos alunos } \\
\text { compreender e explicar fenômenos naturais e tecnologias presentes no seu } \\
\text { dia-a-dia. }\end{array}$ \\
\hline SD04 & $\begin{array}{l}\text { Conteúdo abstrato e } \\
\text { pouco intuitivo }\end{array}$ & $\begin{array}{l}\text { Olicenciando refere-se a tópicos da física quântica que gerariam dificuldades } \\
\text { para os alunos construírem modelos mentais na tentativa de visualizarem } \\
\text { fenômenos microscópicos que não fazem parte de sua realidade intuitiva. }\end{array}$ \\
\hline SD05 & $\begin{array}{l}\text { Domínio do conteúdo } \\
\text { Complexo }\end{array}$ & $\begin{array}{l}\text { O licenciando refere-se à complexidade da física quântica por se tratar de } \\
\text { uma área situada nas fronteiras do conhecimento, que requer a integração } \\
\text { de diversos conhecimentos físicos e matemáticos para sua compreensão. }\end{array}$ \\
\hline
\end{tabular}

Fonte: elaborado pelos autores.

Quadro 2 - Categorias associadas aos saberes pedagógicos

\begin{tabular}{|l|l|l|}
\hline \multicolumn{3}{|c|}{ Saberes Pedagógicos (SP) } \\
\hline Código & \multicolumn{1}{|c|}{ Categorias } & \multicolumn{1}{c|}{ Definição } \\
\hline SP01 & Saber ensinar e saber fazer & $\begin{array}{l}\text { O licenciando pondera sobre habilidades envolvidas no ensino } \\
\text { da física quântica para a educação básica. }\end{array}$ \\
\hline SP02 & $\begin{array}{l}\text { Necessidade de preparo pedagógi- } \\
\text { co e conceitual }\end{array}$ & $\begin{array}{l}\text { O licenciando atribui a si a necessidade de se preparar pedagógi- } \\
\text { ca e conceitualmente para ensinar física quântica. }\end{array}$ \\
\hline SP03 & $\begin{array}{l}\text { Domínio das metodologias de en- } \\
\text { sino }\end{array}$ & $\begin{array}{l}\text { O licenciando considera a utilização de diversos recursos e estra- } \\
\text { tégias nas aulas de física quântica, tais como: abordagens epis- } \\
\text { temológicas e históricas, experimentação, uso de vídeos e simu- } \\
\text { ladores, aspectos CTS, leitura de textos de divulgação cientifica, } \\
\text { textos originais de cientistas, etc. }\end{array}$ \\
\hline SP04 & Abordagem introdutória & $\begin{array}{l}\text { O licenciando pondera sobre a escolha de alguns tópicos da físi- } \\
\text { ca quântica para serem apresentados em nível introdutório, sem } \\
\text { maior aprofundamento conceitual ou matemático, alertando } \\
\text { para os riscos de superficialidade na abordagem. }\end{array}$ \\
\hline SP05 & Difícil para aprender e ensinar & $\begin{array}{l}\text { O licenciando adverte para tópicos de física quântica que acre- } \\
\text { dita ser de difícil aprendizado para os alunos do ensino médio e } \\
\text { desafiadores para o professor ensinar. }\end{array}$ \\
\hline SP06 & Possível aprender & $\begin{array}{l}\text { O licenciando mobiliza sentidos sobre quais tópicos de física } \\
\text { quântica os alunos do ensino médio possivelmente aprende- } \\
\text { riam. }\end{array}$ \\
\hline
\end{tabular}

Fonte: elaborado pelos autores. 
Quadro 3 - Categorias associadas aos saberes curriculares

\begin{tabular}{|c|c|c|}
\hline \multicolumn{3}{|c|}{ Saberes Curriculares (SC) } \\
\hline Código & Categorias & Definição \\
\hline SCO1 & Selecionar o conteúdo & $\begin{array}{l}\text { O licenciando atribui sentidos para a seleção de tópicos da física } \\
\text { quântica a serem ensinados, por exemplo, como forma de traba- } \\
\text { lhar noções sobre a natureza da ciência, de modo considerado } \\
\text { acessível aos alunos e levando em conta a realidade escolar. }\end{array}$ \\
\hline $\mathrm{SCO}$ & Selecionar estratégias de ensino & $\begin{array}{l}\text { O licenciando mobiliza saberes sobre como selecionar estraté- } \\
\text { gias de ensino para trabalhar os tópicos da física quântica. }\end{array}$ \\
\hline SCO3 & Ensino qualitativo & $\begin{array}{l}\text { O licenciando mobiliza sentidos sobre o ensino de física quântica } \\
\text { a partir de abordagens predominantemente qualitativas. }\end{array}$ \\
\hline SCO4 & Romper com o ensino tradicional & $\begin{array}{l}\text { O licenciando refere-se a um suposto rompimento com o ensino } \\
\text { tradicional, privilegiando metodologias não meramente instru- } \\
\text { cionais e explanatórias centradas no professor. }\end{array}$ \\
\hline SC05 & $\begin{array}{l}\text { Desenvolvimento da formação ci- } \\
\text { dadã }\end{array}$ & $\begin{array}{l}\text { O ensino de física quântica contribuiria para o desenvolvimento } \\
\text { do pensamento crítico e reflexivo, para a formação de um cida- } \\
\text { dão mais consciente dos problemas que envolvem ciência, tec- } \\
\text { nologia, cultura e sociedade. }\end{array}$ \\
\hline SC06 & História da Ciência & $\begin{array}{l}\text { Desenvolver o ensino da física quântica por perspectivas históri- } \\
\text { cas possibilitaria a compreensão da ciência como atividade hu- } \\
\text { mana que se desenvolve em determinados contextos históricos, } \\
\text { políticos, sociais, econômicos e culturais. }\end{array}$ \\
\hline SCO7 & Quebra de Paradigmas & $\begin{array}{l}\text { O licenciando mobiliza sentidos ao ensino da física quântica } \\
\text { destacando a quebra de paradigma que ela representa, com o } \\
\text { conhecimento do aluno passando também por modificações sig- } \\
\text { nificativas em relação aos conceitos da física clássica. }\end{array}$ \\
\hline SC08 & Formalismo matemático & $\begin{array}{l}\text { O licenciando considera não ser necessário ensinar a física quân- } \\
\text { tica com uma abordagem matemática. }\end{array}$ \\
\hline
\end{tabular}

Fonte: elaborado pelos autores.

\section{Bases Empíricas para a Categorização}

Nesta seção ilustramos as bases empíricas da categorização proposta, relacionando trechos dos discursos dos estudantes aos saberes e suas respectivas categorias. Trabalhando sobre a superfície linguística, geramos os objetos discursivos que interpretamos elaborando as categorias apresentadas.

No quadro 4 são mostrados enunciados de Rafa nos quais podemos verificar a manifestação de sentidos relacionados a determinados saberes de acordo com as categorias propostas. Na transcrição dos enunciados, manteve-se a forma de expressão tão próxima quanto possível do registrado nas entrevistas.

Quadro 4 - Exemplos de saberes mobilizados por Rafa em seus enunciados

\begin{tabular}{|l|c|}
\hline \multicolumn{1}{|c|}{ Enunciados de Rafa } & Saberes \\
\hline Você tem que saber o mundo em que você vive né, você tem que saber como cidadão mesmo. O que eles se ques- & SD01 \\
tionam é o seguinte: "o que vai mudar na minha vida saber mecânica quântica ou eu saber cosmologia, o que vai & SD02 \\
mudar?" Eu falo que não vai mudar nada na sua vida, mas do mesmo jeito "o que muda na sua vida você saber que & SP04 \\
a Terra que gira em torno do Sol e não o contrário" [...] Então se foram descobertas novas coisas a partir do século & SC05 \\
XX, por que quê você não tem que saber?! Você tem que saber, você tem que saber que o universo se deforma. Você & \\
tem que saber que o tempo é relativo e não é uma constante. Você tem que saber essas coisas, eu acho importante, & \\
e a mecânica quântica é a mesma coisa. Você tem que saber como se comporta o átomo, as partículas, que não é & \\
determinístico. Eu acho legal saber isso aí, mesmo que seja uma coisa meio superficial você tem que saber. & \\
\hline Olha, possível é, só não sei te dizer como [ensinar quântica]. Eu acho que eu tenho que pesquisar. Eu acho que & SP02 \\
nada é impossível. Você tem que pesquisar um jeito legal. O que vai interferir vai ser: a superficialidade, o grau de & SP06 \\
aprofundamento que você vai chegar, e também se você vai chegar num grau que você vai ficar naquela coisa & SP05 \\
que, "ah eu acredito, mas não sei o porquê". Mas a maioria das coisas no ensino médio é assim né? Você acredita, & SC01 \\
mas não sabe o porquê, mesmo sem saber explicar direito. Então, possível eu acho que é. & \\
\hline
\end{tabular}


O grau de abstração seria a primeira [dificuldade para ensinar]. Ele [o aluno] tem que ter um alto grau de abstração para conseguir aceitar coisas que não são triviais e que não fazem parte do cotidiano dele. Você não vai conseguir aproximar coisas do cotidiano pra dar exemplo pra ele. Então são coisas que ele não vê, na realidade. Então é por isso, já tem que ter certo grau de abstração para você conseguir entender as coisas. Você não tem as coisas assim determinísticas, isso é bem difícil.

Não me sinto preparado nenhum pouco pra ensinar mecânica quântica [...]. la requerer muito estudo da minha parte e de todos. [...] talvez se eu soubesse como explicar, tivesse um insight. Ah, dá para explicar desse jeito, aí sim eu daria. Ah, descobri um jeito legal de explicar dualidade onda partícula pros alunos, porque eles vão entender bem o conceito, vão saber diferenciar bem as duas coisas, então aí eu abordaria com certeza, mas como eu não sei um jeito, então eu não abordaria, mas se eu descobrisse com certeza eu abordaria.

Esse negócio de fundamentar na matemática, não sei se os alunos do ensino médio compreendem muito bem. $O$ que tá provando na matemática pra eles meio que tanto faz como tanto fez, entendeu? Quer dizer nada aquilo ali pra ele. Acho que você vai ter esse viés matemático mais no ensino superior mesmo. Eu vejo por mim; quando tu vê que lá no ensino médio, no fundamental II, a gente não entendia nada que a professora falava na demonstração dela. Era uma boa professora, em matemática no caso né, explicava super bem, mas quando ela ia lá formular a demonstração pra explicar, ninguém entendia nada e ninguém estava nem um pouco interessado pra entender. $O$ que a gente queria saber era qual exercício ia cair na prova, ela passava o exemplo e aí sim ficava tudo bem. Eu vou entender o exemplo pra ficar tudo bem, pra conseguir replicar o que você tá fazendo na minha prova.

Eu acho que quanto mais metodologia você usar melhor né, quanto mais você conseguir agrupar. Ora dar um viés histórico, ora em CTS, um viés experimental, conseguir com o mesmo assunto né, você estaria fazendo um pluralismo metodológico. Você está captando os alunos, um aqui na parte experimental, outro na parte histórica e assim vai. Eu acho que é interessante.

Para você conseguir aproximar o aluno do cotidiano dele, você não vai conseguir explicar como é que funciona com outras coisas, seria mais como conceito de mundo mesmo, né. Para ele saber que tem coisas que não funcionam como ele imaginaria que funcionasse, ó, "a mecânica quântica é diferente, no mundo pequeno é diferente as coisas"

Eu acho que eu usaria o Phet, por ser um jeito mais interativo. De mostrar visualmente pra eles seria usando o Phet, eu não vejo outra maneira. Eu acho que eu começaria com o simulador, eu ia falar, ol ha o que acontece, olha o que acontece agora, e depois eu tentaria explicar o porquê, pra meio que gerar uma curiosidade né, e depois introduziria o conteúdo. Não sei se seria muito eficiente, mas eu faria isso.

Fonte: elaborado pelos autores.

A categoria SP02 é a mais evidenciada em seus discursos, com a estudante atribuindo a si a necessidade de estudar e compreender a física quântica e de se preparar pedagogicamente para ensiná-la. Provavelmente em decorrência disso, SD05 não é evidenciada em suas falas. Outra categoria frequentemente mencionada é a SP05, segundo a qual ela avalia que os temas de física quântica são complexos e difíceis de serem ensinados e aprendidos. Ambas as categorias se referem às dificuldades que Rafa considera para o ensino e aprendizagem da física quântica. Seus dizeres estão relacionados às suas experiências frente a esses conteúdos durante sua trajetória educacional, funcionando como uma das condições de produção de sentidos.

Três categorias identificadas aproximadamente com a mesma frequência em seus discursos compõem os saberes disciplinares: SD01, onde considera a física quântica importante para a formação de um cidadão contemporâneo; SD02, que se refere a uma necessária compreensão do mundo pelo entendimento de fenômenos naturais e desenvolvimentos tecnológicos explicados pela quântica; e SD04, pela qual avalia que os conceitos da física quântica são de difícil concretização nos processos mentais dos alunos, o que gera dificuldades para sua compreensão. Nos discursos de Rafa a categoria SD03 é evidenciada quando ela coloca que estes conceitos, além de complexos, são abstratos e pouco intuitivos. Suas produções de sentidos possivelmente são decorrentes de uma formação tradicional em física quântica que, até cursar a disciplina em questão, não visava um ensino qualitativo com abordagens culturais e sociais, nem considerava possibilidades metodológicas para a inserção desse tema na educação básica. 
No quadro 5, apresentamos evidências empíricas de saberes mobilizados por Caio em relação com seus dizeres.

Quadro 5 - Exemplos de saberes mobilizados por Caio em seus enunciados

\begin{tabular}{l} 
Enunciados de Caio \\
\hline Um questionamento de muitos alunos é "se eu quero ser advogado, se eu quero ser artista, qual é a lógica eu seguir \\
uma grade curricular pré-estabelecida com conteúdos que não vão me interessar e que não vão ser úteis para o \\
dia-a-dia do meu trabalho?" Mas uma coisa que eu acho fundamental é esse desenvolvimento de senso crítico \\
gerado pela ciência. Independente do aluno depois não ter nenhum contato com a carreira tecnológica, todo esse \\
choque de realidade, dessa contra intuição, dessa ideia do quê é ciência, do quê é questionar, do quê é pesquisar. \\
Eu acho que isso tudo é muito produtivo para a formação do cidadão.
\end{tabular}

[...] Ainda assim, de forma qualitativa, é possível dar uma noção de como a natureza se comporta. Então você se preocupa em falar como ocorreu historicamente e qualitativamente como é o comportamento.

Utilizar um vídeo didático, um simulador de experimento. É claro que fica aquela coisa 'acredita em mim, no que eu estou dizendo e que o simulador esta mostrando.' Mas, enfim, você vai tentar incentivar o aluno a correr atrás de mais coisas. Eu acho que o caráter qualitativo é ótimo, pelo menos pelos objetivos que eu entendo da quântica no ensino médio. Eu acho que eles são acessíveis para os alunos do ensino médio. [...]. Dependendo da resistência de cada aluno, com documentário, com simulador, com um experimento se tiver a infraestrutura. Um recurso que é muito comum pelo menos para partícula-onda, por exemplo, é aquele filme que a professora tem: um filmezinho impresso com riscos pretos e um laser. Então mesmo com pouca estrutura até dá para fazer alguns experimentos para começar a mostrar para os alunos que algumas coisas acontecem e que não estão no dia-a-dia dele.

Bom, acho que a primeira dificuldade vai ser a tentativa de associar aquele conhecimento a própria realidade do dia-a-dia. [...] Então, eu acho que a tentativa dele trazer aquilo para o mundo real e de perceber que a bola não tem um comportamento quântico, que a pessoa passando pela porta não tem comportamento quântico, e que ele está sendo levado a acreditar porque eu estou falando que para pequenas dimensões esses comportamentos aparecem. Então, acho que uma das principais dificuldades [...] é essa distorção da realidade. É ele perceber que aquilo que eu estou falando não condiz nada do dia-a-dia dele [...] Bom, querendo ou não isso vai acabar batendo um pouco até em física l, quando ele tiver contado com mecânica, quando ele perceber que a cadeira sem exercer força ela vai parar, por questão de atrito e tudo. Mas, intuitivamente a força está associada ao movimento e não a aceleração né? Então, eu acho que em quântica essa quebra de paradigma é muito maior, porque ele não tem como experimentar mesmo no dia-a-dia dele aquilo. Então, eu acho que uma das principais dificuldades é essa, é o aluno querer transpor para a realidade dele e não conseguir.

A matematização é um pouco complicada. Eu não sei se faz sentido usar tempo de aula que poderia ser aplicado nessa lógica mais qualitativa. Então, ao invés de fazer discussões das opiniões dos alunos com relação a como ocorre à dualidade partícula-onda e o que ela realmente é, eu teria que usar tempo de aula para apresentar esse formalismo e tentar resolver em contas, o que eu tenho a impressão de que a maior parte dos alunos irá resolver operacionalmente, mas não teria muita noção do que é aquilo. Você vai dar uma noção do que aquilo significa. Então eu não sei se a profundidade que você vai alcançar no ensino médio é suficiente para justificar você usar. Então eu acabaria me preocupando muito mais em qualitativo, em interpretação, na questão conceitual do que o formalismo matemático..

É claro que tem a questão do aluno acabar vivenciando o cotidiano dele, ver raio $X$, ver célula fotovoltaica, e talvez seja legal ele ter uma associação disso com a sala de aula. Eu acho que é uma das coisas mais legais ele ter contato com a possibilidade dessa quebra de paradigma que a ciência proporciona, por ser algo que não tá tentando ser dogmático. Por ser algo que tem na sua estrutura. Acho que é muito legal para gerar esse choque de realidade.

Sim, me sinto preparado para ensinar física quântica. Eu estudei bastante, pesquisei bastante sobre, discuti bastante sobre, tive a oportunidade de ter as minhas ideias confrontadas com pessoas que tem opiniões diferentes. Esse último ponto que eu acabei de falar ele é legal porque eventualmente os alunos poderão ter ideias diferentes e na experiência que eu tive, eu vi o professor tratando de quatro opiniões diferentes na semana de aula, sendo administradas e tiveram seu espaço. Eu me sinto confortável de tratar esses conteúdos, porque eu li bastante, eu me sinto confortável para entender as opiniões diferentes, para entender as formas de interpretar a quântica, como também para introduzir o conteúdo. Eu tive que tomar bastante cuidado na disciplina para escrever meus relatórios, para me preparar para as discussões, a questão não é saber, mas de se sentir confortável mesmo. Eventualmente posso cometer erros, falar alguma besteira, mas não será por falta de preparo, é porque acontece mesmo.

O efeito fotoelétrico no simulador. Eles testarem frequências diferentes e começar associar frequência e energia: 'esse daqui com mais energia conseguiu arrancar um elétron e esse com menos já não tinha energia suficiente. Mas aí se eu boto vários de uma energia menor não dá certo.' Então começar a fazer esses links e isso é legal para quando se trabalha no simulador o aluno acaba tendo esse contato né, ele pode testar e tal. 
Identificam-se nos discursos de Caio as categorias referentes aos saberes disciplinares, sendo que as mais recorrentes correspondem a SD01, SD02 e SD05. SD01 manifesta-se quando Caio atribui importância para a inserção da física quântica no ensino médio, enquanto que a categoria SD02 é evidenciada onde ele justifica essa importância para que o aluno possa compreender e explicar fenômenos em seu dia-a-dia. A categoria SD05 corresponde ao seu domínio do conteúdo. Durante toda a pesquisa, Caio pareceu demonstrar conhecer certos conceitos da quântica, bem como assumiu durante a disciplina o papel de tirar dúvidas e explicar aspectos da teoria a seus colegas, em um ato de antecipação à sua condição de professor; ele já se colocava nessa posição. Nas categorias SD03 e SD04 é possível identificar que Caio não desconsidera o fato dos conceitos serem abstratos, pouco intuitivos e complexos para o aluno do ensino médio. Entretanto, ele argumenta que tais dificuldades podem ser contornadas.

Sobre as categorias referentes aos saberes curriculares, SC06 e SC07 destacam-se por Caio considerar que a inserção da física quântica no ensino médio pode acontecer a partir da abordagem de aspectos da história da ciência, promovendo modificações significativas em relação aos conceitos da física clássica, enfatizando-se a quebra de paradigmas que a quântica representa. A categoria $\mathrm{SC0} 3$ é evidenciada por ele considerar que o ensino qualitativo pode contribuir mais efetivamente com a aprendizagem de temas da quântica do que um ensino focado em aspectos matemáticos. As categorias SC02, SC04, SC05 e SP03 são identificadas nos momentos em que Caio atribui sentidos às estratégias de ensino por ele conhecidas e sobre quais podem ser empregadas, levando em conta a suposta condição da escola e de seus futuros alunos.

Ele considera viável um ensino qualitativo que desenvolva a autonomia, reflexão e criticidade. Das sete categorias correspondentes aos saberes pedagógicos, cinco foram evidenciadas e a que mais se sobressaiu foi a SP01, onde Caio atribui a si o saber ensinar e o saber fazer. Pois, segundo ele, durante toda a sua formação se dedica para poder, em um futuro próximo, ensinar essa ciência. Ele mobiliza saberes para determinados temas que podem ser apresentados de modo introdutório, sem aprofundamento no formalismo matemático, o que é evidenciado na categoria SP04. Caio evidencia ainda as categorias SP06 e SP07, uma vez que ele acredita na possibilidade de que a aprendizagem de aspectos da quântica estimule os alunos para quererem aprender cada vez mais.

Mesmo encontrando-se em seu processo de formação inicial, Caio demonstra certo domínio conceitual da disciplina e de determinados saberes pedagógicos. Ele parece sentirse seguro para selecionar quais temas da física quântica seriam importantes para o trabalho no ensino médio e identificar em quais deles os alunos possivelmente teriam dificuldades. Ele diz estar disposto a recorrer a estratégias e recursos que se adequem com a realidade escolar que encontrar. Todos estes elementos fazem parte de seu imaginário sobre o que é ser um professor de física. Imaginário este que não é influenciado somente pelas condições de produções de sentidos com as quais Caio teve contato direto, mas que é constituído historicamente e compartilhado socialmente em um processo esquecido pelo sujeito. Tratase do efeito ideológico elementar de que fala a $A D$, responsável pela ilusão da transparência da linguagem e do sujeito como fonte do sentido. 


\section{Alguns Sentidos Mobilizados}

Nesta seção detalhamos aspectos da análise discursiva realizada, destacando alguns sentidos mobilizados por Caio e Rafa ao responderem as perguntas na entrevista e que se vinculam à categorização proposta para os saberes. Procuramos associar os discursos dos estudantes a certa formação discursiva sobre o ensino da quântica, representada por determinados trabalhos reportados na literatura que foram utilizados na disciplina. Sondamos, assim, aspectos do processo discursivo em voga.

Para Rafa, a importância da inserção da física quântica no ensino médio consistiria em permitir que os alunos possam compreender melhor "o mundo em que vivem". Ao atribuírem sentidos aos fenômenos quânticos, os alunos possivelmente perceberiam a influência da física quântica em seu cotidiano, seja na compreensão do funcionamento de dispositivos tecnológicos, de fenômenos naturais, ou na constituição de um senso crítico sobre a ciência. Vale notar que em determinados momentos da entrevista, tanto Rafa quanto Caio destacam que a suposta "influência da física quântica no cotidiano" das pessoas não seria algo trivial de se abordar. Em determinados momentos, Rafa passa a criticar a noção de que o ensino da quântica estaria diretamente ligado com a compreensão do funcionamento dos aparatos tecnológicos que dela se servem. Trata-se de uma crítica pertinente a uma propalada contextualização do ensino da quântica e de sua aproximação com o cotidiano do aluno. Entre afirmar que certos dispositivos tecnológicos atuais funcionam com base em princípios e fenômenos quânticos e desenvolver uma compreensão conceitual da quântica, há todo um espaço de mediação didática não trivial. O fato de Rafa e Caio problematizarem essa concepção um tanto ingênua acerca do ensino da quântica, indica uma reflexão para além de um senso comum colocando-se na posição de professores.

Rafa e Caio consideram que a aprendizagem da física quântica pode contribuir para a formação cidadã, independentemente de qual área do conhecimento a pessoa venha estudar ou atuar futuramente. Além disso, ambos destacam a quebra de paradigma que a física quântica representa, explicando fenômenos que a física clássica não conseguia, elaborando novos conceitos e constituindo uma diferente visão de mundo com interpretações probabilísticas para os fenômenos microscópicos. Isto representa uma apropriação por parte desses estudantes da formação discursiva legitimada pela comunidade científica a respeito da física quântica; um discurso institucional, oficial. Caio atribui ao ensino da física quântica a possibilidade de discutir aspectos de como a ciência é construída a partir da análise de episódios da história da ciência, mobilizando sentidos em contraposição à apresentação de uma ciência dogmática que se desenvolve linearmente.

Tal posição está em concordância, por exemplo, com Pinto e Zanetic (1999, p. 20), que reforçam a "significativa contribuição da história e da filosofia da ciência para a constituição de um moderno ensino de física para o ensino médio e para mostrar que a física quântica também é cultura". Caio também considera o uso de recursos experimentais no ensino médio, seja por aparatos simples ou simuladores virtuais, mencionando exemplos de como trabalhar com experimentos em sala de aula, em particular um que foi mostrado pela professora na disciplina. 
De maneira geral, os sentidos atribuídos à importância do ensino da quântica na educação básica envolvem o desenvolvimento de uma formação cidadã crítica e reflexiva; a compreensão sobre o que é ciência reconhecendo-a como uma construção humana; incentivar o interesse pela ciência; e possibilitar a compreensão de princípios físicos e conceitos para explicar fenômenos naturais e tecnologias atuais. Esses sentidos manifestos por Caio e Rafa são veiculados em estudos acadêmicos e disciplinas que compõem o currículo do curso de licenciatura ao qual estão vinculados, fazendo parte de suas memórias discursivas. Trata-se da manifestação do interdiscurso; o já dito que sustenta os dizeres possíveis, dentre os quais se situa a disciplina cursada com a abordagem que a docente responsável conferiu à mesma.

Rafa e Caio consideram ser possível promover o ensino da física quântica na educação básica. Entretanto, Rafa afirma: "Olha, possível é, só não sei te dizer como. Eu acho que eu tenho que pesquisar. Eu acho que nada é impossível". O fato de Rafa não se considerar preparada para ensinar física quântica é compreensível devido estar em seu processo de formação inicial. Além disso, ela ressalta o fato dos conceitos quânticos não serem intuitivos. Em determinados momentos da entrevista, ela se reporta às suas próprias dificuldades no aprendizado da quântica. Como indicado na literatura, um dos aspectos que dificulta a inserção da física quântica no ensino médio é o fato dos docentes não sentirem-se confortáveis para ensinála (MONTEIRO; NARDI; BASTOS FILHO, 2009; SABINO; PIETROCOLA, 2016; SILVA NETTO; CAVALCANTI; OSTERMANN; 2015). Este parece ser o caso de Rafa, pois se evidencia em seu discurso a necessidade de constituir sentidos sobre os saberes pedagógicos ao afirmar que não está preparada para ensinar quântica. Por sua vez, Caio parece sentir-se seguro para abordar temas de física quântica no ensino médio, evidenciando certo domínio das categorias propostas para os sabres disciplinares, pedagógicos e curriculares, expressandose com aparente convicção.

Há cerca de duas décadas, autores como Pinto e Zanetic (1999) já destacavam algumas dificuldades para introduzir a física quântica no ensino médio, que se manifestaram também nos discursos dos estudantes envolvidos nesta pesquisa, evidenciando que tais dificuldades permanecem como preocupações para os futuros professores de física.

\footnotetext{
A primeira refere-se ao formalismo matemático inerente à descrição quântica; outra, diz respeito às novidades conceituais que se distanciam da Física Clássica de forma ainda mais acentuada do que esta da Física do senso comum; a terceira dificuldade está relacionada com o tratamento experimental dos temas quânticos. Assim, temos que ir em busca de formas alternativas e tentativas. (PINTO; ZANETIC, 1999, p. 8).
}

Rafa e Caio também consideram uma dificuldade o fato da física quântica ser abstrata e distanciar-se ainda mais da percepção sensorial do que a física clássica, lidando com fenômenos que não pertencem ao domínio macroscópico. Tal dificuldade pode contribuir para um desinteresse nas aulas, ainda que isso também ocorra em aulas de física clássica. Caio recorre a uma comparação entre fenômenos da física clássica e da quântica, com o intuito de embasar sua opinião de que os fenômenos quânticos são mais complexos.

Com relação à complexidade do formalismo matemático da física quântica e a suposta necessidade dos conceitos físicos clássicos estarem bem consolidados, Caio acredita que a abordagem qualitativa pode sopesar tais necessidades. Ostermann et al. (2009), Pinto e Zanetic (1999), e Silva e Almeida (2011) estão entre os autores que alertam que o uso excessivo do formalismo matemático no ensino da física quântica, seja no ensino médio ou nos cursos de licenciatura, pode não contribuir para um ensino científico crítico, cultural e 
emancipatório. No trecho "então o ensino médio eu penso meio que desse jeito né, você ia complicar muito mais", Rafa afirma que inserir o formalismo matemático nas aulas de física quântica seria um complicador para a aprendizagem dos alunos no ensino médio. Ela coloca que os alunos do ensino médio sentem-se desestimulados, muitas vezes não compreendem as equações e deduções matemáticas e, quando se interessam, é porque tal exercício "cairá na prova".

Manifesta-se nos discursos de Rafa e Caio a ideia de que as dificuldades em abordar a física quântica na escola básica podem ser reduzidas através de um planejamento adequado que considere os recursos acessíveis aos estudantes, uma abordagem qualitativa sem formalismos matemáticos complexos e com o auxílio de elementos da história da ciência. Assim, parece que há clareza acerca dos problemas, sobre o que seria desejável obter como resultado dos processos de ensino e aprendizagem, mas o desafio consiste em trilhar caminhos para sua efetivação, como se pode interpretar dos dizeres de Rafa.

Selecionar o que ensinar não é uma tarefa simples quando se trata de inserir física quântica no ensino médio, em um cenário de currículos já sobrecarregados. Caio e Rafa refletem sobre quais tópicos da física quântica trabalhariam. Inicialmente, Caio considera possível abordar a quantização da radiação na interação com a matéria através do efeito fotoelétrico e a dualidade onda-partícula. Ele menciona a abordagem do efeito fotoelétrico utilizando um simulador que contemple particularidades do fenômeno, que poderia auxiliar o aluno a atribuir sentidos aos novos conceitos. Mesmo Rafa se considerando despreparada para ensinar, mobiliza sentidos sobre o uso de recursos possíveis de serem empregados no ensino médio e trata da questão de usar os recursos a partir das necessidades de cada aluno. Como abordagens, ela diz que utilizaria aspectos das relações CTS, episódios da história da ciência e a noção de quebra de paradigma com o intuito de promover uma gradativa construção do conhecimento de seus futuros alunos.

Caio afirma que discutiria a questão do não determinismo, ao passo que Rafa demonstrou uma inquietação acerca desse aspecto da quântica. Afinal, não é tão simples admitir que, conforme ressalta Pessoa Jr. (2005), a teoria só trata do que é mensurável. Uma suposta realidade não observada não é descritível pelo nosso atual estágio de conhecimento e linguagem. A realidade observada é fruto da interação entre sujeito e objeto, decorrente da tese de que o colapso da função de onda é provocado pela medição. Rafa diz acreditar que a indeterminação da teoria quântica poderá ser explicada futuramente. O próprio fato de existirem diversas interpretações possíveis da teoria quântica ilustra que, mesmo diante de objetos matemáticos, os sentidos podem vir a serem outros, revelando um caráter polissêmico dos conceitos quânticos que, ao menos em nosso atual estágio de conhecimento, não pode ser eliminado objetivamente.

Evidenciamos nos dizeres de Rafa e Caio efeitos das condições de produção a que esses estudantes estão sujeitos. No contexto imediato, a disciplina cursada com o enfoque planejado pela docente responsável; em perspectiva mais ampla, os conhecimentos constituídos por eles no decorrer de suas formações iniciais em outros componentes curriculares e o imaginário que compartilham, desde a época de estudantes na educação básica, sobre o que é ser um professor. Durante o curso de licenciatura em física, os estudantes são inseridos em uma formação discursiva e ideológica que abarca discursos produzidos institucionalmente por professores e pesquisadores sobre a profissão docente e o ensino de ciências. Entendemos que o processo em questão diz respeito à constituição de um discurso acadêmico sobre o ensino de ciências na educação básica. 


\section{Considerações Finais}

No contexto de uma disciplina que trabalha aspectos conceituais e epistemológicos da física quântica, analisamos os sentidos que dois estudantes atribuem para questões relacionadas à inserção da quântica na educação básica, estabelecendo relações entre tais sentidos e a constituição dos saberes docentes da formação profissional conforme compreendidos por Tardif (2014). A metodologia desenvolvida viabilizou a obtenção de material empírico e a elaboração de categorias que proporcionam uma caracterização de certos saberes mobilizados pelos sujeitos desta pesquisa. Tais categorias são um refinamento da caracterização dos saberes de Tardif, fruto de um trabalho interpretativo diante dos discursos elaborados pelos estudantes entrevistados. Consideramos sua proposição como uma contribuição à área de pesquisa em educação em ciências.

Pela análise realizada evidenciamos a produção de sentidos sobre três saberes docentes (saberes disciplinares, curriculares e os pedagógicos). Os saberes mobilizados por Rafa estão em maior evidência nas categorias dos saberes disciplinares, provavelmente devido ela não ter tido contato com determinadas condições de produções de sentidos, como disciplinas a respeito de práticas pedagógicas que possibilitariam a mobilização de sentidos para este saber específico. Caio articulou os saberes disciplinares e curriculares com os pedagógicos, produzindo determinados sentidos sobre os saberes experienciais. Isto é um indício de que tais saberes começam a ser mobilizados ainda na formação inicial, na medida em que o estudante se coloca na posição de professor e exercita essa posição, compartilhando um imaginário social sobre a profissão e, eventualmente, tomando contato com certas realidades escolares, por exemplo, pelos programas de estágio supervisionado.

O ensino da física quântica na educação básica apresenta desafios e diversos deles foram manifestados pelos estudantes. No entanto, eles consideram que esse ensino pode ser viável a partir de um planejamento adequado que considere a limitação de recursos materiais na escola, que utilize uma abordagem qualitativa sem formalismos matemáticos complexos e com o auxílio da história da ciência. Ao longo de sua vida como estudante nos diversos níveis de ensino, passando pela formação inicial, durante sua atuação profissional, pelas experiências pessoais e aquelas compartilhadas com os colegas, bem como na participação em programas de formação continuada, o professor constitui e mobiliza saberes que integram sua memória discursiva. Talvez, uma adequada síntese da formação ideológica atual sobre a docência possa ser expressa pelas palavras de Tardif (2014, p. 39):

[...] o professor ideal é alguém que deve conhecer sua matéria, sua disciplina e seu programa, além de possuir certos conhecimentos relativos às ciências da educação e à pedagogia e desenvolver um saber prático baseado em sua experiência cotidiana com os alunos.

$\mathrm{Na}$ busca por esse ideal, há novas possibilidades. Apesar de resistentes, disciplinas, programas, currículos e conhecimentos científicos mudam. Outros sentidos são atribuídos, inclusive para a própria prática docente. Sentidos esses que se constroem com base em pesquisas, reflexões e ações com as quais se espera que o presente trabalho possa colaborar. 


\section{Referências}

ALMEIDA, M. J. P. M. Discursos da ciência e da escola: ideologia e leituras possíveis. Campinas: Mercado das Letras, 2004.

BOGDAN, R. C.; BIKLEN, S. K. Investigação qualitativa em educação: uma introdução a teoria e aos métodos. Porto: Porto Editora, 1994.

LIBÂNEO, J. C. Organização e gestão da escola. 5 ed. Goiânia: Alternativa, 2004.

MAINGUENEAU, D. Discurso e análise do discurso. São Paulo: Parábola Editorial, 2015.

MONTEIRO, M. A.; NARDI, R.; BASTOS FILHO, J. B. B. A sistemática incompreensão da teoria quântica e as dificuldades dos professores na introdução da física moderna e contemporânea no ensino médio. Ciência \& Educação, Bauru, v. 15, n. 3, p. 557-580, 2009. DOI: https://doi.org/10.1590/S151673132009000300007

ORLANDI, E. P. Análise de discurso: princípios e procedimentos. 9. ed. Campinas: Pontes, 2010.

OSTERMANN, F.; CAVALCANTI, C. J. H.; PRADO, S. D.; RICCI, T. S. F. Fundamentos da física quântica à luz de um interferômetro virtual de Mach-Zehnder. Revista Electrónica de Enseñanza de las Ciencias, Vigo, v. 8, n. 3, p. 1094-1116, 2009.

PESSOA JR., O. Conceitos da física quântica. São Paulo: Livraria da Física, 2005.

PINTO, A. C.; ZANETIC, J. É possível levar a física quântica para o ensino médio? Caderno Catarinense de Ensino de Física, Florianópolis, v. 16, n. 1, p. 7-34, 1999.

SABINO, A. R.; PIETROCOLA, M. Saberes docentes desenvolvidos por professores do ensino médio: um estudo de caso com a inserção da física moderna. Investigações em Ensino de Ciências, Porto Alegre, v. 21, n. 2, p. 200-216, 2016.

SHULMAN, L. S. Those who understand: knowledge growth in teaching. Educational Researcher, Washington, v. 15, p. 4-14, 1986.

SILVA, A. C.; ALMEIDA, M. J. P. M. Física quântica no ensino médio: o que dizem as pesquisas. Caderno Brasileiro de Ensino de Física, Florianópolis, v. 28, n. 3, p. 624-653, 2011. DOI: https://doi. org/10.5007/2175-7941.2011v28n3p624

SILVA NETTO, J.; CAVALCANTI, C. J. H.; OSTERMANN, F. Estratégias discursivas adotadas por professores em formação na compreensão do fenômeno da complementaridade em atividades didáticas mediadas pelo interferômetro virtual de Mach-Zehnder. Revista Brasileira de Pesquisa em Educação em Ciências, Belo Horizonte, v. 15, n. 2, p. 293-320, 2015.

TARDIF, M. Saberes docentes e formação profissional. 17. ed. Petrópolis: Vozes, 2014.

TARDIF, M. Saberes profissionais dos professores e conhecimentos universitários. Revista Brasileira de Educação, Rio de Janeiro, n. 13, jan/fev/mar/abr. 2000.

TARDIF, M.; LESSARD, C. O trabalho docente: elementos para uma teoria da docência como profissão de interações humanas. 6. ed. Petróplois: Vozes, 2011.

TRIVIÑOS, A. N. S. Introdução à pesquisa em ciências sociais: a pesquisa qualitativa em educação. São Paulo: Atlas, 1987. 